\title{
Greater fear of re-injury and increased tibial translation in patients who later sustain an ACL graft rupture or a contralateral ACL rupture: a pilot study
}

Sofi Tagesson and Joanna Kvist

Linköping University Post Print

\section{Tweet}

N.B.: When citing this work, cite the original article.

This is an electronic version of an article published in:

Sofi Tagesson and Joanna Kvist, Greater fear of re-injury and increased tibial translation in patients who later sustain an ACL graft rupture or a contralateral ACL rupture: a pilot study, 2016, Journal of Sports Sciences, (34), 2, 125-132.

Journal of Sports Sciences is available online at informaworld ${ }^{\mathrm{TM}}$ :

http://dx.doi.org/10.1080/02640414.2015.1035668

Copyright: Taylor \& Francis: SSH Journals

http://www.tandf.co.uk/journals/default.asp

Postprint available at: Linköping University Electronic Press

http://urn.kb.se/resolve?urn=urn:nbn:se:liu:diva-123478 


\section{Greater fear of re-injury and increased tibial translation in patients who later sustain an ACL graft rupture or a contralateral ACL rupture}

\section{A pilot study}

Sofi Tagesson RPT, PhD, Joanna Kvist RPT, PhD

Corresponding author: Sofi Tagesson, Dept. of Medical and Health Sciences, Division of Physiotherapy Linköping University, SE-581 83 Linköping, Sweden. Tel: +46 013-286898; fax: +46 10-1031706. E-mail: sofi.tagesson@liu.se Joanna Kvist, Dept. of Medical and Health Sciences, Division of Physiotherapy Linköping University, SE-581 83 Linköping, Sweden. Tel: +46 013-284664; fax: +4610-1031706.E-mail:joanna.kvist@liu.se

Running head: Fear of re-injury and subsequent ACL injury

\section{Acknowledgement}

The authors thank the Orthopedic Department at the University Hospital, Linköping for co-operation and Dr. Clare Ardern, School of Allied Health, La Trobe University, Melbourne, Australia and Division of Physiotherapy, Linköping University, Linköping, Sweden for valuable comments on the manuscript.

\section{Funding}

This study was supported by the Faculty of Health Sciences at Linköping University and by grants from the Swedish Centre for Research in Sports.

\section{Conflict of interest}

The authors declare that they have no conflict of interest. 


\section{Abstract}

The aim was to compare fear of re-injury, patient reported function, static and dynamic tibial translation and muscle strength assessed before and 5 weeks after an ACL reconstruction between individuals who sustained a subsequent ACL graft rupture or a contralateral ACL injury within 5 years after the reconstruction, and individuals with no subsequent injury. Nineteen patients were investigated before, and 5 weeks after an ACL reconstruction with a quadruple hamstring tendon graft. At 5 years follow up, 3 patients had sustained an ACL graft rupture and 2 patients had sustained a contralateral ACL rupture. Fear of re-injury, confidence with the knee, patient reported function, activity level, static and dynamic tibial translation and muscle strength were assessed. The re-injured group reported greater fear of reinjury and had greater static tibial translation in both knees before the ACL reconstruction compared to those who did not sustain another ACL injury. There were no other differences between groups. In conclusion, fear of re-injury and static tibial translation before the index ACL reconstruction were greater in patients that later on suffered an ACL graft rupture or a contralateral ACL rupture. These factors may predict a subsequent ACL injury.

Key words: ACL reconstruction, graft rupture, subsequent ACL injury, fear of reinjury, tibial translation 


\section{Introduction}

Patients with an ACL injury or ACL reconstruction have an increased risk of sustaining a subsequent ACL injury (Orchard, Seward, McGivern, \& Hood, 2001;

Paterno, Rauh, Schmitt, Ford, \& Hewett, 2012; Sward, Kostogiannis, \& Roos, 2010).

Four to $8 \%$ of patients will sustain a graft rupture on the index knee within five years after an ACL reconstruction. During the same period, approximately 5-6\% will sustain a contralateral ACL rupture (Ahlden et al., 2012; Crawford, Waterman, \& Lubowitz, 2013; Hettrich, Dunn, Reinke, Group, \& Spindler, 2013; Lind, Menhert, \& Pedersen, 2012; Salmon, Russell, Musgrove, Pinczewski, \& Refshauge, 2005; Shelbourne, Gray, \& Haro, 2009; Spindler et al., 2013). Young age (Ahlden et al., 2012; Faltstrom, Hagglund, Magnusson, Forssblad, \& Kvist, 2014; Hettrich et al., 2013; Kvist, Kartus, Karlsson, \& Forssblad, 2014; Lind et al., 2012; Magnussen et al., 2012; Maletis, Inacio, \& Funahashi, 2013; Shelbourne et al., 2009; Wasserstein et al., 2013; Webster, Feller, Leigh, \& Richmond, 2014) and returning to high activity level after an ACL injury (Borchers, Pedroza, \& Kaeding, 2009; Faltstrom, Hagglund, \& Kvist, 2013; Salmon et al., 2005; Shelbourne et al., 2009; Sward et al., 2010) have been highlighted as the most important risk factors for sustaining a contralateral ACL injury or an ACL graft rupture. Age may be a proxy for neuromuscular maturation, and altered neuromuscular control of the knee and hip and impaired postural stability has been reported to predict a second ACL injury (Paterno et al., 2010). Increased static tibial translation is associated with an increased risk of an initial ACL injury (Smith et al., 2012). However, whether static or dynamic tibial translation affects the risk of a subsequent ACL injury is not well investigated. Besides, psychological variables might be of importance. Fear of reinjury is reported to have negative influence on the rehabilitation after ACL 
reconstruction (te Wierike, van der Sluis, van den Akker-Scheek, Elferink-Gemser, \& Visscher, 2013), and moreover, fear of re-injury is associated with the knee function (Chmielewski et al., 2008; Hartigan, Lynch, Logerstedt, Chmielewski, \& Snyder-Mackler, 2013; te Wierike et al., 2013). Yet, it is unknown if fear of re-injury is associated to the actual risk of re-injury in individuals with ACL reconstruction.

It has been raised a need for studies evaluating predictors for subsequent ACL injuries (Wright, Magnussen, Dunn, \& Spindler, 2011). Tibial translation, knee function and psychological variables measured before ACL reconstruction may provide information that could be used to predict the risk for future injuries. Further, post-operative rehabilitation may need to be more individualized, addressing specific individual predictive factors, in order to reduce the risk of re-injury. In a previous study, we reported the effect of ACL reconstruction on static and dynamic translation and muscle activation in nineteen patients (Tagesson, Oberg, \& Kvist, 2010). In a follow-up, five years after the reconstruction, five patients had sustained an ACL graft rupture or a contralateral ACL rupture. The purpose of the present study was to compare fear of re-injury, patient reported knee function and static and dynamic tibial translation assessed before and 5 weeks after the ACL reconstruction, and muscle strength assessed before the ACL reconstruction, between the individuals who sustained a new knee injury, and those with intact ACL reconstruction (i.e. no subsequent injury).

\section{Methods}

Ethical approval was granted by the local Ethics Committee (Dnr M70-08). All patients gave written informed consent prior to their participation. This study, with 
case series study design, is a follow up on an earlier published study presenting tibial translation after ACL reconstruction. The original study evaluated static tibial translation and dynamic tibial translation and EMG during gait and rehabilitation exercises before and 5 weeks after an ACL reconstruction (Tagesson et al., 2010).

\section{Patients}

Nineteen patients were investigated before, and 5 weeks after an ACL reconstruction with a quadruple hamstring tendon graft. Participants were recruited consecutively from patients that were diagnosed with unilateral ACL rupture that was at most 4.5 years old, and were on the waiting list for ACL reconstruction in one orthopaedic unit in southeastern Sweden. The ACL reconstructions were performed from October 2004 to May 2006. Exclusion criteria included total rupture of medial collateral ligament (MCL), lateral collateral ligament (LCL) or posterior cruciate ligament (PCL), meniscus sutures in the injured knee joint, total rupture of ACL, MCL, LCL or PCL, or reconstruction on the contralateral knee. All patients followed a structured rehabilitation program after the ACL reconstruction. At follow up, 5 years (median, range 4-5 years) after the ACL reconstruction, 3 patients had sustained an ACL graft rupture and 2 patients had sustained a contralateral ACL rupture. The subsequent ACL injuries had occurred between 2 and 4 years postsurgery (missing data on one individual). In the present study the re-injured group (5 patients; 2 men, median age 21 (17-25)) were compared to the patients who did not have a subsequent injury; the non re-injured group (14 patients; 9 men, median age 21 (16-31)). A 5 year follow up on the non re-injured group has been published before (Tagesson, Oberg, \& Kvist, 2014). 


\section{Assessments}

Assessments were performed 2 weeks before (median, range 0-4 weeks) and exactly 5 weeks after an ACL reconstruction. An overview of the objective assessments and self-reported scores used at the different time points in the study are displayed in table 1.

Self-reported scores

Activity level was assessed with the Tegner score (Tegner \& Lysholm, 1985). Selfreported knee function was assessed with the Lysholm score (Tegner \& Lysholm, 1985) and the Knee Injury and Osteoarthritis Outcome Score (KOOS) (Roos, Roos, Lohmander, Ekdahl, \& Beynnon, 1998). Fear of re-injury and confidence with the knee joint were assessed with 4 separate questions that have been modified from the KOOS, the ACL Quality of Life questionnaire (ACL QoL) (Mohtadi, 1998) and The Tampa Scale of Kinesiophopia (TSK) (Vlaeyen, Kole-Snijders, Boeren, \& van Eek, 1995) (Tables 2 and 3).

\section{Objective assessments}

Sagittal tibial translation during instrumented Lachman test and during gait was measured with the CA-4000 electrogoniometer (OSI Inc., Hayward CA, USA). The total static tibial translation was measured during the instrumented Lachman test at 90N and 134N (134N only before the ACL reconstruction). Dynamic translation was measured as the maximal anterior tibial translation during gait. Detailed information about the assessments with the CA-4000 has been published previously (Tagesson et al., 2010). Isokinetic quadriceps and hamstrings muscle strength was evaluated at 60 
deg/s using a Biodex dynamometer (Biodex Medical Systems, New York). Peak torque was measured for 3 repetitions.

\section{Data acquisition and analysis}

The computerised goniometer linkage, CA-4000, was used to measure the knee flexion angle and sagittal tibial translation. The goniometer has been described previously (Kvist \& Gillquist, 2001). The CA-4000 was zeroed at the beginning of each assessment, with the subject lying supine on the examination table and the knee relaxed to full extension. To identify the reference position at each flexion angle for the calculation of tibial translation during activity, a passive knee extension was performed by the examiner with the patient sitting on an examination table in a position of $70^{\circ}$ hip flexion. With the patient relaxed, the examiner first flexed the knee to more than $100^{\circ}$, and then extended it into hyperextension. Dynamic anterior tibial translation was calculated by subtracting the tibial position recorded at each flexion angle during the passive extension, from the tibial position recorded at the same flexion angle during gait (Kvist \& Gillquist, 2001), which is presented as maximal anterior tibial translation. For the Lachman test the total anterior-posterior translation in the sagittal plane was recorded and is presented as total static tibial translation. Data were sampled from the potentiometers by a computer at a rate of $1000 \mathrm{~Hz}$. Detailed information about the data acquisition and analysis has been published previously (Tagesson et al., 2010). 


\section{Statistical Analyses}

Analyses were performed using IBM SPSS Statistics version 20-21 (SPSS Inc., Chicago, IL, USA). An independent samples t-test was used to compare the tibial translation and muscle strength between the groups. Other variables were analyzed with independent samples Mann-Whitney U tests. Significance was set at $P<.05$ for all analyses.

\section{Results}

There were three (60\%) females in the re-injured group and five (36\%) females in the non re-injured group. There were no significant differences between groups regarding sex or age.

Self-reported scores

Activity level before the injury and activity level before the ACL reconstruction did not differ significantly between the re-injured group and the non re-injured group (Table 2). The patients that suffered a re-injury had at the time for their subsequent injury resumed their pre-injury activity and activity level (median 7, range 4-7, missing data on one individual). In the non re-injured group the activity level at the 5 year follow up was in median 4 (range 3-7) as compared to in median 7 (range 7-10) before the injury. Self-reported knee function did not differ significantly between groups before surgery or at 5 weeks after surgery (Table 2 and 3).

The re-injured group estimated significantly greater fear of re-injury at the preoperative assessment compared to the non re-injured group (median 13 (1-20) vs. 28 (0-100), $\mathrm{p}=0.005$. Response model 100mm VAS. The score 100 indicates no 
fear/high confidence, table 2.). Confidence with the knee joint did not differ significantly between groups pre-operatively (table 2). At 5 weeks after surgery, there were no significant differences between the groups in fear of re-injury or confidence with the knee joint (Table 3). However, the two patients that later suffered a contralateral ACL rupture reported great fear of re-injury (score 0, scale 0100).

\section{Objective assessments}

Before the ACL reconstruction the re-injured group had significantly greater static tibial translation in both knees compared to the non re-injured group (Lachman 134N injured knee $11.1 \pm 1.5 \mathrm{~mm}$ vs. $8.4 \pm 2.0 \mathrm{~mm}, \mathrm{p}=0.013$; uninjured knee $7.8 \pm 1.3 \mathrm{~mm}$ vs. $6.0 \pm 1.7 \mathrm{~mm}, \mathrm{p}=0.045$, table 4). At 5 weeks after the ACL reconstruction the static tibial translation did not differ significantly between groups. There were no significant differences between the re-injured group and the non re-injured group in dynamic tibial translation or muscle strength (Table 2 and 4) measured before surgery. At 5 weeks after surgery, there were no significant differences between the groups in dynamic tibial translation (Table 4).

\section{Discussion}

This study showed that the patients who suffered an ACL graft rupture or a contralateral ACL rupture after the index surgery, had greater pre-operative static tibial translation in both knees, and reported greater fear of re-injury compared to patients who did not suffer a subsequent injury. In addition, the two patients who suffered a contralateral ACL rupture reported extreme fear of re-injury at 5 weeks after the ACL reconstruction. These results suggest that a higher level of fear of re- 
injury before surgery and early in recovery from surgery might increase the risk for a subsequent ACL injury. In line with the present study, psychological factors have earlier been identified as risk factors for sport injuries (Dunn, Smith, \& Smoll, 2001; Ivarsson \& Johnson, 2010; Ivarsson, Johnson, \& Podlog, 2013; Johnson \& Ivarsson, 2011; Junge, 2000; Wiese-Bjornstal, 2010). Psychosocial stressors, coping resources and situation dependent emotional states may affect the risk of a sport injury (Junge, 2000). Moreover, returning to high activity level after an ACL injury has previously been identified as an important risk factor for subsequent ACL injury (Borchers et al., 2009; Faltstrom et al., 2013; Salmon et al., 2005; Shelbourne et al., 2009; Sward et al., 2010). The result in the current study comply with this, as the patients who suffered a subsequent ACL injury had returned to their pre-injury activity level, while the patients with an intact ACL reconstruction had lowered their activity level. These results may be interpreted as individuals who return to sports after ACL reconstruction, in spite of fear of re-injury, might have an increased risk for a subsequent ACL injury.

Fear of re-injury is common after ACL reconstruction (Flanigan, Everhart, Pedroza, Smith, \& Kaeding, 2013; Heijne, Axelsson, Werner, \& Biguet, 2008; Kvist, Ek, Sporrstedt, \& Good, 2005), and earlier studies have described its importance for the post-operative outcome. High fear of re-injury has been reported to be associated with worse patient reported and measured knee function (Chmielewski et al., 2008; Hartigan et al., 2013; Lee, Karim, \& Chang, 2008; Lentz et al., 2009; te Wierike et al., 2013), and to be correlated to low knee-related quality of life (Kvist et al., 2005) in patients with ACL injury and reconstruction. Greater fear of re-injury has also been associated with lower rates of return to sports (Ardern, Taylor, Feller, \& 
Webster, 2012; Flanigan et al., 2013; Kvist et al., 2005; Lee et al., 2008; Lentz et al., 2012; te Wierike et al., 2013; Tripp, Stanish, Ebel-Lam, Brewer, \& Birchard, 2007). It has been suggested that fear of re-injury may limit functional outcome after ACL reconstruction (Chmielewski et al., 2008). Patients with poor knee function after ACL injury have been reported to have higher levels of fear of re-injury compared to well-functioning patients (Hartigan et al., 2013). Hartigan et al have suggested that there is a relationship between fear of re-injury and self-reported knee function, muscle strength and the ability to perform 6-meter timed hop test (Hartigan et al., 2013). In the current study we found that fear of re-injury was increased in the patients who suffered a new injury. However, there were no differences in dynamic knee stability, measured as dynamic sagittal tibial translation using the CA-4000 electrogoniometer, between the re-injured group and the non re-injured group. Thus, it is possible that fear of re-injury is a risk factor for a subsequent ACL injury. Increased fear may affect the physical performance and this in turn could affect the risk of injury. Though, the importance of fear of re-injury and the underlying mechanisms, and associations between fear and dynamic knee stability are yet unclear and require further investigation. The need of better understanding of determinants and consequences of perceived susceptibility to sport injuries have also been raised by others (Deroche, Stephan, Brewer, \& Le Scanff, 2007).

The finding of greater static tibial translation in the patients who subsequently suffered an ACL graft rupture or a contralateral ACL rupture in the present study is comparable to results in previous studies (Smith et al., 2012). Myer et al reported that greater static tibial translation may contribute to increased risk of ACL injury (Myer, Ford, Paterno, Nick, \& Hewett, 2008). However, that study screened laxity 
measurements on subjects before their ACL injury, while in the present study we performed bilateral measurements in patients with ACL injury before and early after their index ACL reconstruction. Woodford-Rogers et al assessed the uninjured knee of ACL injured individuals and found that individuals with ACL injury have greater static tibial translation compared to uninjured individuals (Woodford-Rogers, Cyphert, \& Denegar, 1994). Moreover, Uhorchak et al found that increased static tibial translation and excessive generalized joint laxity increased the risk for ACL injury (Uhorchak et al., 2003). Similarly, a higher prevalence of generalized joint laxity in patients with ACL rupture compared to uninjured controls has also been described (Hewett et al., 2010; Kramer, Denegar, Buckley, \& Hertel, 2007; Ramesh, Von Arx, Azzopardi, \& Schranz, 2005).

The current study contributes new knowledge by showing a prospective association between fear of re-injury and tibial translation and subsequent injury. A strength of the study is that the patients underwent a comprehensive evaluation, performed by the same experienced physiotherapist (S.T.), 2 weeks before the index ACL reconstruction, and at 5 weeks after the index ACL reconstruction. A limitation with this study is the small study sample and thereby restricted ability to generalize the results. However, despite the small study sample there were statistically significant differences between groups in tibial translation and fear of re-injury. The small study sample involve a risk of type II errors. Therefore, some variables which were not significant may still be worth including in larger studies, for example sex, Tegner score before injury, and the questions " how fearful are you of your knee giving way when you exercise?" and "do you have confidence in your knee joint?”. Although we compared pre-surgery variables in patients with subsequent ACL injury with patients 
with intact ACL graft, we cannot be sure of the causal relationships. Fear of re-injury and tibial translation should be taken into account in future studies aiming to reveal characteristics that predisposes an individual to subsequent injuries after an ACL reconstruction. This pilot study suggests that assessing fear of re-injury and tibial translation in the clinical routine before ACL reconstruction may be valuable in order to identify people who might be at risk of a new ACL injury.

\section{Conclusions}

This pilot study of 19 patients suggests that patients who suffered a subsequent ACL graft rupture or a contralateral ACL injury following their index ACL reconstruction, estimated greater fear of re-injury before surgery and had greater pre-operative static tibial translation in both knees, compared to patients who did not suffer a subsequent ACL injury.

\section{Key points}

Findings: Individuals who suffered an ACL graft rupture or a contralateral ACL injury following their index ACL reconstruction, estimated greater fear of re-injury before their surgery and had greater pre-operative static tibial translation in both knees, compared to individuals who did not suffer a subsequent injury. Implications: Fear of re-injury and tibial translation should be taken into account in future studies aiming to reveal characteristics that predisposes an individual to subsequent injuries after an ACL reconstruction. 
Caution: This is a small sample study and the results need to be confirmed in future studies. 


\section{References}

Ahlden, M., Samuelsson, K., Sernert, N., Forssblad, M., Karlsson, J., \& Kartus, J. (2012). The Swedish National Anterior Cruciate Ligament Register: a report on baseline variables and outcomes of surgery for almost 18,000 patients. The American journal of sports medicine, 40(10), 2230-2235.

Ardern, C. L., Taylor, N. F., Feller, J. A., \& Webster, K. E. (2012). Fear of re-injury in people who have returned to sport following anterior cruciate ligament reconstruction surgery. Journal of science and medicine in sport / Sports Medicine Australia, 15(6), 488-495.

Borchers, J. R., Pedroza, A., \& Kaeding, C. (2009). Activity level and graft type as risk factors for anterior cruciate ligament graft failure: a case-control study. The American journal of sports medicine, $37(12), 2362-2367$.

Chmielewski, T. L., Jones, D., Day, T., Tillman, S. M., Lentz, T. A., \& George, S. Z. (2008). The association of pain and fear of movement/reinjury with function during anterior cruciate ligament reconstruction rehabilitation. The Journal of orthopaedic and sports physical therapy, 38(12), 746-753.

Crawford, S. N., Waterman, B. R., \& Lubowitz, J. H. (2013). Long-term failure of anterior cruciate ligament reconstruction. Arthroscopy : the journal of arthroscopic \& related surgery : official publication of the Arthroscopy Association of North America and the International Arthroscopy Association, 29(9), 1566-1571.

Deroche, T., Stephan, Y., Brewer, B. W., \& Le Scanff, C. (2007). Predictors of perceived susceptibility to sport-related injury. Personality and Individual Differences, 43, 2218-2228.

Dunn, E. C., Smith, R. E., \& Smoll, F. L. (2001). Do sport-specific stressors predict athletic injury? Journal of science and medicine in sport / Sports Medicine Australia, 4(3), 283-291.

Faltstrom, A., Hagglund, M., \& Kvist, J. (2013). Patient-reported knee function, quality of life, and activity level after bilateral anterior cruciate ligament injuries. The American journal of sports medicine, 41(12), 2805-2813.

Faltstrom, A., Hagglund, M., Magnusson, H., Forssblad, M., \& Kvist, J. (2014). Predictors for additional anterior cruciate ligament reconstruction: data from the Swedish national ACL register. Knee surgery, sports traumatology, arthroscopy : official journal of the ESSKA, 10.1007/s00167-0143406-6.

Flanigan, D. C., Everhart, J. S., Pedroza, A., Smith, T., \& Kaeding, C. C. (2013). Fear of reinjury (kinesiophobia) and persistent knee symptoms are common factors for lack of return to sport after anterior cruciate ligament reconstruction. Arthroscopy : the journal of arthroscopic \& related surgery : official publication of the Arthroscopy Association of North America and the International Arthroscopy Association, 29(8), 1322-1329.

Hartigan, E. H., Lynch, A. D., Logerstedt, D. S., Chmielewski, T. L., \& Snyder-Mackler, L. (2013). Kinesiophobia after anterior cruciate ligament rupture and reconstruction: noncopers versus potential copers. The Journal of orthopaedic and sports physical therapy, 43(11), 821-832.

Heijne, A., Axelsson, K., Werner, S., \& Biguet, G. (2008). Rehabilitation and recovery after anterior cruciate ligament reconstruction: patients' experiences. Scandinavian journal of medicine \& science in sports, 18(3), 325-335.

Hettrich, C. M., Dunn, W. R., Reinke, E. K., Group, M., \& Spindler, K. P. (2013). The rate of subsequent surgery and predictors after anterior cruciate ligament reconstruction: two- and 6-year followup results from a multicenter cohort. The American journal of sports medicine, 41(7), 15341540.

Hewett, T. E., Lynch, T. R., Myer, G. D., Ford, K. R., Gwin, R. C., \& Heidt, R. S., Jr. (2010). Multiple risk factors related to familial predisposition to anterior cruciate ligament injury: fraternal twin sisters with anterior cruciate ligament ruptures. British journal of sports medicine, 44(12), 848855. 
Ivarsson, A., \& Johnson, U. (2010). Psychological factors as predictors of injuries among senior soccer players. A prospective study. Journal of sports science \& medicine, 9(2), 347-352.

Ivarsson, A., Johnson, U., \& Podlog, L. (2013). Psychological predictors of injury occurrence: a prospective investigation of professional Swedish soccer players. Journal of sport rehabilitation, 22(1), 19-26.

Johnson, U., \& Ivarsson, A. (2011). Psychological predictors of sport injuries among junior soccer players. Scandinavian journal of medicine \& science in sports, 21(1), 129-136.

Junge, A. (2000). The influence of psychological factors on sports injuries. Review of the literature. The American journal of sports medicine, 28(5 Suppl), S10-15.

Kramer, L. C., Denegar, C. R., Buckley, W. E., \& Hertel, J. (2007). Factors associated with anterior cruciate ligament injury: history in female athletes. The Journal of sports medicine and physical fitness, 47(4), 446-454.

Kvist, J., Ek, A., Sporrstedt, K., \& Good, L. (2005). Fear of re-injury: a hindrance for returning to sports after anterior cruciate ligament reconstruction. Knee surgery, sports traumatology, arthroscopy : official journal of the ESSKA, 13(5), 393-397.

Kvist, J., \& Gillquist, J. (2001). Sagittal plane knee translation and electromyographic activity during closed and open kinetic chain exercises in anterior cruciate ligament-deficient patients and control subjects. The American journal of sports medicine, 29(1), 72-82.

Kvist, J., Kartus, J., Karlsson, J., \& Forssblad, M. (2014). Results from the Swedish national anterior cruciate ligament register. Arthroscopy : the journal of arthroscopic \& related surgery : official publication of the Arthroscopy Association of North America and the International Arthroscopy Association, 30(7), 803-810.

Lee, D. Y., Karim, S. A., \& Chang, H. C. (2008). Return to sports after anterior cruciate ligament reconstruction - a review of patients with minimum 5-year follow-up. Annals of the Academy of Medicine, Singapore, 37(4), 273-278.

Lentz, T. A., Tillman, S. M., Indelicato, P. A., Moser, M. W., George, S. Z., \& Chmielewski, T. L. (2009). Factors associated with function after anterior cruciate ligament reconstruction. Sports health, 1(1), 47-53.

Lentz, T. A., Zeppieri, G., Jr., Tillman, S. M., Indelicato, P. A., Moser, M. W., George, S. Z., \& Chmielewski, T. L. (2012). Return to preinjury sports participation following anterior cruciate ligament reconstruction: contributions of demographic, knee impairment, and self-report measures. The Journal of orthopaedic and sports physical therapy, 42(11), 893-901.

Lind, M., Menhert, F., \& Pedersen, A. B. (2012). Incidence and outcome after revision anterior cruciate ligament reconstruction: results from the Danish registry for knee ligament reconstructions. The American journal of sports medicine, 40(7), 1551-1557.

Magnussen, R. A., Lawrence, J. T., West, R. L., Toth, A. P., Taylor, D. C., \& Garrett, W. E. (2012). Graft size and patient age are predictors of early revision after anterior cruciate ligament reconstruction with hamstring autograft. Arthroscopy : the journal of arthroscopic \& related surgery : official publication of the Arthroscopy Association of North America and the International Arthroscopy Association, 28(4), 526-531.

Maletis, G. B., Inacio, M. C., \& Funahashi, T. T. (2013). Analysis of 16,192 anterior cruciate ligament reconstructions from a community-based registry. The American journal of sports medicine, 41(9), 2090-2098.

Mohtadi, N. (1998). Development and validation of the quality of life outcome measure (questionnaire) for chronic anterior cruciate ligament deficiency. Am J Sports Med, 26(3), 350-359.

Myer, G. D., Ford, K. R., Paterno, M. V., Nick, T. G., \& Hewett, T. E. (2008). The effects of generalized joint laxity on risk of anterior cruciate ligament injury in young female athletes. The American journal of sports medicine, 36(6), 1073-1080.

Orchard, J., Seward, H., McGivern, J., \& Hood, S. (2001). Intrinsic and extrinsic risk factors for anterior cruciate ligament injury in Australian footballers. The American journal of sports medicine, 29(2), 196-200. 
Paterno, M. V., Rauh, M. J., Schmitt, L. C., Ford, K. R., \& Hewett, T. E. (2012). Incidence of contralateral and ipsilateral anterior cruciate ligament $(A C L)$ injury after primary $A C L$ reconstruction and return to sport. Clinical journal of sport medicine : official journal of the Canadian Academy of Sport Medicine, 22(2), 116-121.

Paterno, M. V., Schmitt, L. C., Ford, K. R., Rauh, M. J., Myer, G. D., Huang, B., \& Hewett, T. E. (2010). Biomechanical measures during landing and postural stability predict second anterior cruciate ligament injury after anterior cruciate ligament reconstruction and return to sport. The American journal of sports medicine, 38(10), 1968-1978.

Ramesh, R., Von Arx, O., Azzopardi, T., \& Schranz, P. J. (2005). The risk of anterior cruciate ligament rupture with generalised joint laxity. The Journal of bone and joint surgery. British volume, 87(6), 800-803.

Roos, E. M., Roos, H. P., Lohmander, L. S., Ekdahl, C., \& Beynnon, B. D. (1998). Knee Injury and Osteoarthritis Outcome Score (KOOS)--development of a self-administered outcome measure. Journal of Orthopaedic \& Sports Physical Therapy, 28(2), 88-96.

Rosnow, R. L., Rosenthal, R., \& Rubin, D. B. (2000). Contrasts and correlations in effect-size estimation. Psychological science, 11(6), 446-453.

Salmon, L., Russell, V., Musgrove, T., Pinczewski, L., \& Refshauge, K. (2005). Incidence and risk factors for graft rupture and contralateral rupture after anterior cruciate ligament reconstruction. Arthroscopy : the journal of arthroscopic \& related surgery : official publication of the Arthroscopy Association of North America and the International Arthroscopy Association, 21(8), 948-957.

Shelbourne, K. D., Gray, T., \& Haro, M. (2009). Incidence of subsequent injury to either knee within 5 years after anterior cruciate ligament reconstruction with patellar tendon autograft. The American journal of sports medicine, 37(2), 246-251.

Smith, H. C., Vacek, P., Johnson, R. J., Slauterbeck, J. R., Hashemi, J., Shultz, S., \& Beynnon, B. D. (2012). Risk factors for anterior cruciate ligament injury: a review of the literature - part 1: neuromuscular and anatomic risk. Sports health, 4(1), 69-78.

Spindler, K. P., Parker, R. D., Andrish, J. T., Kaeding, C. C., Wright, R. W., Marx, R. G., ... Group, M. (2013). Prognosis and predictors of ACL reconstructions using the MOON cohort: a model for comparative effectiveness studies. Journal of orthopaedic research : official publication of the Orthopaedic Research Society, 31(1), 2-9.

Sward, P., Kostogiannis, I., \& Roos, H. (2010). Risk factors for a contralateral anterior cruciate ligament injury. Knee surgery, sports traumatology, arthroscopy : official journal of the ESSKA, 18(3), 277291.

Tagesson, S., Oberg, B., \& Kvist, J. (2010). Tibial translation and muscle activation during rehabilitation exercises 5 weeks after anterior cruciate ligament reconstruction. Scandinavian journal of medicine \& science in sports, 20(1), 154-164.

Tagesson, S., Oberg, B., \& Kvist, J. (2014). Static and dynamic tibial translation before, 5 weeks after, and 5 years after anterior cruciate ligament reconstruction. Knee Surg Sports Traumatol Arthrosc. DOI: 10.1007/s00167-014-3279-8., 10.1007/s00167-014-3279-8.

te Wierike, S. C., van der Sluis, A., van den Akker-Scheek, I., Elferink-Gemser, M. T., \& Visscher, C. (2013). Psychosocial factors influencing the recovery of athletes with anterior cruciate ligament injury: a systematic review. Scandinavian journal of medicine \& science in sports, 23(5), 527-540.

Tegner, Y., \& Lysholm, J. (1985). Rating systems in the evaluation of knee ligament injuries. Clinical Orthopaedics \& Related Research(198), 43-49.

Tripp, D. A., Stanish, W., Ebel-Lam, A., Brewer, B. W., \& Birchard, J. (2007). Fear of Reinjury, Negative Affect, and Catastrophizing Predicting Return to Sport in Recreational Athletes With Anterior Cruciate Ligament Injuries at 1 Year Postsurgery. Rehabilitation Psychology, 52(1), 74-81.

Uhorchak, J. M., Scoville, C. R., Williams, G. N., Arciero, R. A., St Pierre, P., \& Taylor, D. C. (2003). Risk factors associated with noncontact injury of the anterior cruciate ligament: a prospective four- 
year evaluation of 859 West Point cadets. The American journal of sports medicine, 31(6), 831842.

Wasserstein, D., Khoshbin, A., Dwyer, T., Chahal, J., Gandhi, R., Mahomed, N., \& Ogilvie-Harris, D. (2013). Risk factors for recurrent anterior cruciate ligament reconstruction: a population study in Ontario, Canada, with 5-year follow-up. The American journal of sports medicine, 41(9), 20992107.

Webster, K. E., Feller, J. A., Leigh, W. B., \& Richmond, A. K. (2014). Younger patients are at increased risk for graft rupture and contralateral injury after anterior cruciate ligament reconstruction. The American journal of sports medicine, 42(3), 641-647.

Wiese-Bjornstal, D. M. (2010). Psychology and socioculture affect injury risk, response, and recovery in high-intensity athletes: a consensus statement. Scandinavian journal of medicine \& science in sports, 20 Suppl 2, 103-111.

Vlaeyen, J. W., Kole-Snijders, A. M., Boeren, R. G., \& van Eek, H. (1995). Fear of movement/(re)injury in chronic low back pain and its relation to behavioral performance. Pain, 62(3), 363-372.

Woodford-Rogers, B., Cyphert, L., \& Denegar, C. R. (1994). Risk factors for anterior cruciate ligament injury in high school and college athletes. Journal of athletic training, 29(4), 343-346.

Wright, R. W., Magnussen, R. A., Dunn, W. R., \& Spindler, K. P. (2011). Ipsilateral graft and contralateral $A C L$ rupture at five years or more following $A C L$ reconstruction: a systematic review. The Journal of bone and joint surgery. American volume, 93(12), 1159-1165. 


\section{Tables}

Table 1 Overview of the objective assessments and self-reported scores used at the different time points in the study.

\begin{tabular}{llll}
\hline Assessment/score & $\begin{array}{l}\text { Before ACL } \\
\text { rec }\end{array}$ & $\begin{array}{l}\text { 5 weeks after } \\
\text { ACL rec }\end{array}$ & Follow up $^{\mathrm{a}}$ \\
\hline Static tibial translation during instrumented Lachman test & $90 \mathrm{~N}, 134 \mathrm{~N}$ & $90 \mathrm{~N}$ \\
Maximum anterior tibial translation during gait & $\mathrm{x}$ & $\mathrm{x}$ \\
& & $\mathrm{x}$ & \\
Isokinetic quadriceps strength & $\mathrm{x}$ & $\mathrm{x}$ \\
Isokinetic hamstring strength & $\mathrm{x}$ & $\mathrm{x}$ & \\
Tegner score & $\mathrm{x}$ & $\mathrm{x}$ & \\
Lysholm score & $\mathrm{x}$ & $\mathrm{x}$ & \\
KOOS & $\mathrm{x}$ & $\mathrm{x}$ & \\
4 questions about fear of giwing way, fear of pain, & & & \\
fear of re-injury and confidence in the knee & &
\end{tabular}

$\overline{{ }^{a}}$ Follow up is at time of re-injury for the re-injured group and at 5 year after the ACL reconstruction for the non reinjured group.

${ }^{\mathrm{b}}$ at time for ACL reconstruction and an retrospective estimation at the assessment before ACL reconstruction 
Table 2 Participant characteristics and self-reported knee function estimated at the assessment before ACL reconstruction, median (range).

\begin{tabular}{|c|c|c|c|c|}
\hline \multicolumn{2}{|c|}{ Score/question } & $\begin{array}{l}\text { Re-injured } \\
(n=5)\end{array}$ & $\begin{array}{l}\text { Non re-injured } \\
(\mathrm{n}=14)\end{array}$ & $\mathbf{P}$ \\
\hline \multicolumn{2}{|l|}{ Age } & $22(17-25)$ & $21(16-31)$ & 0.620 \\
\hline \multicolumn{2}{|c|}{ Sex (male/female) } & $2 / 3$ & $9 / 5$ & 0.491 \\
\hline \multicolumn{2}{|c|}{ Time from injury to surgery (months) } & $10(5-35)$ & $10(2-55)$ & 0.823 \\
\hline \multicolumn{2}{|c|}{ Time from injury to assessment before ACL rec (months) } & $9(5-35)$ & $10(2-55)$ & 0.754 \\
\hline \multicolumn{2}{|c|}{ Tegner score } & $7(4-9)$ & $7(7-10)$ & 0.257 \\
\hline \multicolumn{2}{|r|}{ before ACL reconstruction } & $4(0-4)$ & $4(3-5)$ & 0.687 \\
\hline \multicolumn{2}{|c|}{ Lysholm score } & $90(33-100)$ & $86(64-100)$ & 1.000 \\
\hline \multirow[t]{5}{*}{ KOOS } & Pain & $92(44-97)$ & $86(72-100)$ & 0.566 \\
\hline & Symptoms & $96(43-100)$ & $91(68-96)$ & 0.687 \\
\hline & Function in Daily Living & $96(72-100)$ & $96(87-100)$ & 0.893 \\
\hline & Function in Sport and Recreation & $70(5-85)$ & $65(25-100)$ & 0.559 \\
\hline & Knee-related Quality of Life & $31(19-56)$ & $38(13-69)$ & 0.687 \\
\hline \multicolumn{2}{|c|}{ How fearful are you of your knee giving way when you exercise?b } & $3(2-54)$ & $32(7-62)$ & 0.343 \\
\hline \multicolumn{2}{|c|}{ To what extent do you have fear of pain when you exercise? ${ }^{\mathrm{b}}$} & $45(8-74)$ & $41(17-98)$ & 0.622 \\
\hline \multicolumn{2}{|c|}{ Do you have confidence in your knee joint? ${ }^{\mathrm{b}}$} & $12(0-48)$ & $29(0-58)$ & 0.186 \\
\hline \multicolumn{2}{|c|}{ How fearful are you of re-injuring your knee? ${ }^{b}$} & $13(1-20)$ & $28(0-100)$ & 0.005 \\
\hline \multicolumn{2}{|c|}{$\begin{array}{l}\text { Isokinetic quadriceps strength ACL deficient leg before ACL rec, } \\
\% \text {, mean } \pm \mathrm{SD}^{\mathrm{c}}\end{array}$} & $93 \pm 13$ & $93 \pm 15$ & 0.936 \\
\hline \multicolumn{2}{|c|}{$\begin{array}{l}\text { Isokinetic hamstring strength ACL deficient leg before ACL rec, } \\
\% \text {, mean } \pm \mathrm{SD}^{\mathrm{c}}\end{array}$} & $99 \pm 20$ & $99 \pm 17$ & 0.988 \\
\hline \multicolumn{5}{|c|}{ a retrospective estimation at the assessment before ACL reconstruction. } \\
\hline
\end{tabular}


Table 3 Self-reported knee function estimated at the assessment 5 weeks after the ACL reconstruction in the reinjured group and the non re-injured group respectively, median (range).

\begin{tabular}{|c|c|c|c|c|}
\hline \multicolumn{2}{|c|}{ Score/question } & \multirow{2}{*}{$\begin{array}{l}\text { Re-injured } \\
(\mathrm{n}=5) \\
79(43-84)\end{array}$} & \multirow{2}{*}{$\begin{array}{l}\text { Non re-injured } \\
(\mathrm{n}=14) \\
62(41-82)\end{array}$} & \multirow{2}{*}{\begin{tabular}{|l|} 
P value \\
0.391 \\
\end{tabular}} \\
\hline Lysholn & core & & & \\
\hline \multirow[t]{5}{*}{ KOOS } & Pain & $78(47-89)$ & $71(44-86)$ & 0.687 \\
\hline & Symptoms & $61(29-79)$ & $54(43-93)$ & 0.622 \\
\hline & Function in Daily Living & $85(72-93)$ & $78(60-97)$ & 0.186 \\
\hline & Function in Sport and Recreation & $10(5-25)$ & $13(5-25)$ & 0.792 \\
\hline & Knee-related Quality of Life & $25(6-38)$ & $22(13-38)$ & 0.964 \\
\hline \multicolumn{2}{|c|}{$\begin{array}{l}\text { To what extent do you have fear of your knee giving way } \\
\text { when you perform the rehabilitation exercises? }\end{array}$} & $76(0-100)$ & $82(48-100)$ & 0.343 \\
\hline \multicolumn{2}{|c|}{$\begin{array}{l}\text { To what extent do you have fear of pain when you perform } \\
\text { the rehabilitation exercises? }\end{array}$} & $77(6-100)$ & $75(38-100)$ & 0.823 \\
\hline \multicolumn{2}{|c|}{ Do you have confidence in your knee joint? ${ }^{a}$} & $23(0-82)$ & $26(9-53)$ & 0.687 \\
\hline \multicolumn{2}{|c|}{ To what extent do you fear re-injury?a } & $43(0-75)$ & $39(14-98)$ & 0.444 \\
\hline
\end{tabular}


Table 4 Total tibial translation $(\mathrm{mm})$ (mean $\pm S D$ ), P-values, effect size (Cohen's d adjusted for unequal sample size (Rosnow, Rosenthal, \& Rubin, 2000) and 95\% confidence intervals between the re-injured group and the non reinjured group, during the Lachman test (La) and maximum anterior tibial translation during gait, assessed before the index ACL reconstruction and 5 weeks after the reconstruction.

\begin{tabular}{|c|c|c|c|c|c|c|c|c|}
\hline \multirow[t]{2}{*}{ Time } & \multirow[t]{2}{*}{ Variable } & \multirow[t]{2}{*}{ Knee } & \multirow{2}{*}{$\begin{array}{l}\text { Re- } \\
\text { injured } \\
(n=5)\end{array}$} & \multirow{2}{*}{$\begin{array}{l}\text { Non re- } \\
\text { injured } \\
(n=14)\end{array}$} & \multirow[t]{2}{*}{$\boldsymbol{P}$} & \multirow[t]{2}{*}{$d$} & \multicolumn{2}{|c|}{$95 \% \mathrm{CI}$} \\
\hline & & & & & & & $\mathrm{L}$ & $\mathrm{U}$ \\
\hline \multirow{6}{*}{$\begin{array}{l}\text { Before ACL } \\
\text { reconstruction }\end{array}$} & La $90 \mathrm{~N}$ & Inj & $8.9 \pm 1.2$ & $6.7 \pm 1.6$ & 0.012 & 1,541 & 0.548 & 3.908 \\
\hline & & Uninj & $6.2 \pm 0.7$ & $5.0 \pm 1.3$ & 0.059 & 1,114 & -0.053 & 2.493 \\
\hline & La $134 \mathrm{~N}$ & Inj & $11.1 \pm 1.5$ & $8.4 \pm 2.0$ & 0.013 & 1,533 & 0.662 & 4.816 \\
\hline & & Uninj & $7.8 \pm 1.3$ & $6.0 \pm 1.7$ & 0.045 & 1,195 & 0.050 & 3.563 \\
\hline & Gait & Inj & $6.7 \pm 1.6$ & $5.7 \pm 1.8$ & 0.315 & 0,571 & -0.977 & 2.862 \\
\hline & & Uninj & $5.5 \pm 3.4$ & $4.8 \pm 1.6$ & 0.540 & 0,344 & -1.694 & 3.121 \\
\hline 5 weeks & La $90 \mathrm{~N}$ & Inj & $6.1 \pm 2.8$ & $6.1 \pm 1.3$ & 0.927 & 0,051 & -1.877 & 2.050 \\
\hline $\begin{array}{l}\text { after ACL } \\
\text { reconstruction }\end{array}$ & Gait & Inj & $5.6 \pm 2.7$ & $4.8 \pm 1.5$ & 0.411 & 64 & -1.208 & 2.816 \\
\hline
\end{tabular}

